\title{
Presencia y participación de la industria española en la producción de cemento en Iberoamérica
}

\author{
JOSE IGNACIO BARON, Director de Exportación SERCOBE
}

JeSUS LAFORGUE, Jefe del Departamento de Estudios y Proyectos SERCOBE

\begin{abstract}
Para considerar el grado y la influencia que en los últimos años la industria española ha tenido en el equipamiento del sector de la industria del cemento en Iberoamérica, es conveniente antes situar y definir, aunque sea en grandes trazos, en primer lugar la exportación española de bienes de equipo y maquinaria, y después la situación y evolución del subsector de empresas constructoras y suministradores de plantas de cemento en nuestro país.

Es suficientemente conocido el espectacular salto que la industria española, en general, y la de bienes de equipo, en particular, ha experimentado en la última década, no sólo en cuanto se refiere a su capacidad productiva, sino también al grado de tecnología empleado, así como a la diversificación y especialización de las empresas del mismo.
\end{abstract}

Si en 1965 la producción total del sector se cifra en 75 mil millones de pesetas, diez años después, aún teniendo en cuenta que la cifra se da en millones de pesetas corrientes, sobrepasa los 400 mil millones. Ello supone un crecimiento en una década del $431 \%$.

En cuanto se refiere a su grado de especialización, basta señalar que sectores de actividad básicos en las industrias y plantas de procesos, como la electrónica profesional, la instrumentación y el control de procesos, la fundición, forja y calderería y construcción mecánica de aceros especiales, aluminio o acero inoxidable, eran o bien desconocidos, o estaban muy débilmente representados en la producción del sector. Hoy no sólo tienen una participación mayoritaria en la actividad del sector, sino que vienen regularmente participando en la exportación.

Al comienzo de la década de los sesenta. la preocupación primordial del sector, después de la etapa de estabilización y ante las cifras de inversión que se barajaban como inversión de bienes de equipo en los sucesivos Planes de Desarrollo, fue la de tratar por todos los medios de defender sus propios intereses, tratando de obtener el mayor grado de participación posible por aplicación de la "Ley de Protección y Defensa de la Industria Nacional" de 1939.

Esta fue la razón básica de la creación de SERCOBE €n el año 1964, y de esos años arranca el espíritu común que alienta el esfuerzo realizado para lograr transformar una industria obsoleta y con limitada capacidad e insuficientemente utillada y equipada, sin disponer de la tecnología adecuada con la que hoy conocemos que no sólo abastece el mercado nacional (con las lógicas limitaciones en determinadas áreas de producción), sino que participa de forma creciente en los mercados exteriores. 
Aunque durante este período y en particular en la década de los años sesenta, la casi totalidad de la capacidad productiva del sector tuvo que estar dedicada al mercado interno, las siguientes consideraciones muestran el grado progresivo de cambio que se estaba produciendo. Basta para ello considerar:

- De una exportación de apenas 1.200 millones de pesetas en 1960, se pasa en 1965 a los 5.300 ; en 1970, a los 26.000 millones; para sobrepasar en 1975 los 90.000 millones de pesetas.

- La participación de las exportaciones industriales en nuestra balanza comercial pasa a tener una importancia creciente y mayoritaria. De representar en los primeros años sesenta menos de un $40 \%$, pasa en 1970 al $70 \%$ y en 1975 a casi el $80 \%$ de las exportaciones totales españolas. A su vez las exportaciones de bienes de equipo representan menos del $10 \%$ al principio de la década, para alcanzar el $25 \%$ en la actualidad.

- El porcentaje de las exportaciones sobre la producción total varía igualmente en el mismo período de menos de un $5 \%$ a superar el $25 \%$.

Es decir, poco más de diez años han bastado para que este sector industrial, de importancia capital en cualquier país en su industrialización y desarrollo económico y de enorme sensibilidad a los cambios de la política económica, de una actitud de desconocimiento total del mercado exterior y la exportación, de la competencia internacional y de todas las implicaciones que ello suponía de sistemas, usos y prácticas comerciales y financieras desconocidas casi generalmente, se pasase a constituir un sector con más éxito y participación variable pero creciente, en los mercados exteriores.

Es conveniente y necesario ahora pasar a analizar, aunque sea brevemente, cómo ha evolucionado la estructura de las ventas del sector y su diversificación geográfica y técnica.

Como antes hemos señalado, tanto en la composición de la producción como de las exportaciones, en el inicio, la base más amplia estaba constituida por los sectores de máquinasherramienta, maquinaria textil, material y maquinaria eléctrica simple, buques y vehículos industriales ligeros.

En casi todos los casos, por no decir en la totalidad, estas ventas suponían el simple suministro de la maquinaria, con su grado de sofisticación y tecnología y por tanto valor añadido relativamente bajo.

Se pasa de este punto a, como decíamos antes, realizar un salto verdaderamente espectacular en el que tienen participación creciente otros campos de actividad con un grado de complejidad e incorporación de tecnología, valor añadido y responsabilidad muchísimo más elevado.

A.sí, las exportaciones no ocasionales, sino regulares de material ferroviario complejo y moderno (locomotoras, trenes-unidad y coches), equipo y material de comunicaciones (sistemas de telefonía, de radio y televisión, y sistemas de enlaces por microondas), electrónica profesional (control de procesos, instrumentación y medida), equipo y material de aviación, etc., son claros exponentes que avalan nuestra afirmación.

Pero además de ello y ya correspondiendo a un nivel que demuestra la "mayoría de edad" aunque dentro de la juventud de la industria española, de forma creciente las exportaciones se materializan a través de la realización de plantas, o proyectos industriales completos en los que se lleva a cabo desde el proyecto y estudios básicos de viabilidad y factibilidad, el suministro de todos los equipos, su montaje e instalación, hasta la entrega de la planta, llegándose incluso a la asistencia técnica continuada posterior y entrenamiento $\mathrm{y}$ formación profesional. 
No constituyen ya casos singulares la contratación de plantas o realizaciones industriales completas bajo el concepto que ha venido a generalizarse como "llave en mano" de plantas de cemento, instalaciones siderúrgicas, ingenios azucareros, centrales hidroeléctricas y termoeléctricas, refinerías, plantas petroquímicas y químicas, etc., donde las referencias de proyectos ejecutados si no puede como es lógico decirse que son muy numerosas, sí que son representativas y diversificadas.

Corresponde ahora, después de la conveniente introducción que hemos hecho para situar el contexto de la industria de bienes de equipo en la actualidad, pasar a analizar el desarrollo y evolución del sector de la maquinaria y equipos para la industria del cemento, objeto de esta conferencia.

Podemos - creo- arriesgarnos a asegurar que uno de los campos de actuación en los que ha sido más sostenida, regular y creciente la consecución de operaciones, junto con el del material ferroviario, maquinaria eléctrica y vehículos industriales, ha sido el del cemento.

El crecimiento y evolución del sector cliente en España en este período, y las disposiciones y regulaciones sucesivas que en España, dictadas por el Ministerio de Industria, han obligado a instalar capacidades mínimas del orden de las más avanzadas en otros países industrializados, así como la adopción de técnicas modernas en materia de control y automatización de procesos, protección del medio ambiente, etc., han forzado a que la industria suministradora se adapte, modernice y adecue a las necesidades determinadas y bajo condiciones técnicas con complejidad creciente.

Por otra parte las tecnologías utilizadas en nuestro país corresponden a las más modernas y avanzadas en el mundo. Si recordamos que los Klockner-Humboldt-Wedag, Polysius, F. L. Smith, Fives-Lille Cail, Vickers, Miag, Allis Chalmers, Fuller, etc., tienen bien sea empresas filiales en España o acuerdos de cesión de licencia o tecnología con fabricantes o sociedades de ingeniería españolas, comprobaremos que no es fácil que exista en el mundo un mercado donde la competencia haya sido tan variada y tan dura como en el nuestro.

En mi opinión personal y creo que para poca fortuna, y este mal se debe extender a la mayoría del resto de los sectores, esta situación no ha ayudado precisamente a la creación de una técnica propia, ni a una adecuada y conveniente estructuración y especialización de las empresas fabricantes, ya que razones de interés y competencia inmediatas en orden a la consecución de pedidos han sido las que han privado, con una política absolutamente miope de gran parte de los productores españoles.

Pero a pesar de ello, este obligado ejercicio ha situado a las empresas de servicios (ingenierías y proyectistas industriales en este campo) y a los fabricantes y constructores de maquinaria, a trabajar con métodos, normas y códigos muy diferentes, así como a conocer los diversos procedimientos y tecnologías con una clara y directa ventaja en cuanto a su adiestramiento y grado de capacitación técnica para el proyecto, suministro y construcción de plantas de cemento.

En cuanto al grado de participación española en el proyecto y suministro de una planta de cemento, la situación ha evolucionado igualmente de forma favorable.

Así, de suponer el aprovisionamiento de equipos, maquinaria y tecnología (excepción hecha de los trabajos de obras civiles y construcción) menos del 35 ó $40 \%$ de una fábrica de 1.000 t/día de capacidad, se ha pasado no solamente a invertir ampliamente estos términos (ya que el suministro nacional llega a ser del orden de un 85-90\%), sino que se ha aumentado muy notablemente el grado de tecnificación con incorporación de los procedimientos más modernos (precalentamiento, automatización y control total del proceso productivo); y aumento de la capacidad de las unidades fundamentales (hornos, molinos e intercambiadores). 
En lo que a ingeniería y proyecto se refiere, diversas empresas empañolas desarrollan desde hace tiempo toda la ingeniería de detalle, los servicios de compra, supervisión y dirección de montaje e incorporan una parte apreciable y creciente de la ingeniería básica y de diseño.

Aún mayor importancia tiene el hecho de que desde hace ya algún tiempo, no solamente en el mercado nacional, sino fundamentalmente en el exterior, firmas españolas del sector están actuando y han llevado a cabo realizaciones concretas de plantas de cemento, c.ctuer.do como contratistas generales, lo cual no sólo supone el reconocimiento de la capacidad empresarial en los mercados internacionales, sino de su grado de competitividad y del prestigio alcanzado para mantener una posición dentro de la cada vez más dura competencia internacional.

En el campo de las realizaciones concretas, como antes indicábamos, ya pueden constatarse los resultados y la experiencia obtenida desde la perspectiva de bastantes países y de casi in decenio. Ello sin duda nos permitirá no sólo exponer una situación de h€cho, sino además deducir unas conclusiones para exponer la siempre difícil previsión y evolic:ón futura.

En la actualidad las actuaciones en temas concretos emprendidos de forma seria y continuada, alcanzan a la casi totalidad de los países iberoamericanos.

Que podamos recordar y sin riesgo de presunción o de magnificar el trabajo y esfuerzo realizado, hasta la fecha empresas y firmas españolas han estudiado, analizado, presentado y discutido ofertas y en general no sólo en una ocasión, sino de forma atenta y continua:da a los siguientes países: Argentina, Chile, Paraguay, Uruguay, Brasil, Bolivia, Ecuador, Venezuela, Colombia, Cuba, México, Rep. Dominicana, San Salvador, Guatemala, Honduras, Costa Rica, Panamá y Haití.

ES d cir, en más de 18 países iberoaméricanos hemos estado atentos a la evolución, cambios y posibilidades de cada uno de los mercados.

Ya en el aspecto de las realizaciones concretas, hasta la fecha se han contratado doce fábriczs de cəmento con realización llave en mano desde España, de las cuales han sido ya tres entregadas de forma totalmente satisfactoria, cumpliendo las especificaciones y garantías contractuales; y las otras cuatro restantes se encuentran en avanzado estado de reaiizeción.

A con 'nuación indicamos algunos datos y referencias de estos proyectos, señalando los correspondientes a Iberoamérica y al resto del mundo:

I B E ROAMERICA

\begin{tabular}{|c|c|c|c|}
\hline Pais & Planta & Empresa & Observaciones \\
\hline Argentina & 1.000 t/día (vía seca) & ZAPACA & en servicio \\
\hline Argen:ina & $\begin{array}{l}1.000 \text { t/día de clínker } \\
\text { (vía seca) }\end{array}$ & $\begin{array}{l}\text { Ampliación de la planta } \\
\text { de Olavarría de Cale- } \\
\text { ra Avellaneda, S. A. }\end{array}$ & en servicio \\
\hline Cúba & $\begin{array}{l}2 \text { líneas de } 22.000 \text { t/día } \\
\text { de clínker (vía seca) }\end{array}$ & $\begin{array}{l}\text { Ampliación planta de } \\
\text { "Rene Arcay" en Mariel }\end{array}$ & en realización \\
\hline República Dominicana & $\begin{array}{c}1.200 \text { t/día de clínker } \\
\text { (vía seca) }\end{array}$ & Cementos Barahona & $\begin{array}{l}\text { en comienzo de reali- } \\
\text { zación }\end{array}$ \\
\hline Costa Rica & 150.000 t/año (vía seca) & CALHIDRA & entregada \\
\hline San Salvador & 260.000 t/año (vía seca) & Cemento Maya & en pruebas \\
\hline Gua:ema'a & 350.000 t/año & CEGUASA & $\begin{array}{l}\text { en comienzo de realiza- } \\
\text { ción }\end{array}$ \\
\hline Brasil & 850 t/día & CIPLAN & en pruebas \\
\hline
\end{tabular}


Además de estos proyectos se realizó una fábrica de cemento en Tetuán, de 400 t/día, así como otra planta de similar capacidad para el Gobierno de la República de Guinea, actualmente en construcción.

Por último, en fecha muy reciente se ha contratado una planta de 3.200 t/día de clínker para la firma CIBINONG, en la República de Indonesia, por vía seca. Es de destacar que en este último caso es la primera vez que se utilizará el sistema de precalcinación desde España, lo cual juntamente con la gran capacidad de la planta y el mercado de que se trata hacen que sea una referencia muy destacada para la industria española.

Además de éstas, en los momentos actuales se encuentran en avanzado estado de negociación 5 proyectos más de cemento en Uruguay, Costa Rica, Ecuador, Brasil y Yugoslavia.

En cuanto se refiere a las tecnologías de base empleadas, se han utilizado en total en estos proyectos en cinco ocasiones licencias de KHD, de MIAG en otras cinco, una de Polysius y otra de Fives-Lille Cail.

En los nuevos proyectos se están utilizando además en uno de ellos la colaboración de Allis Chalmers.

Es decir, de nuevo constatamos la universalidad y versatilidad de la industria del país, que puede alcanzar - como vemos- colaboraciones con empresas muy distintas geográfica y técnicamente.

En nuestra opinión, tres o cuatro son las empresas o grupos industriales españoles con dimensión, capacidad, espíritu y vocación exterior y experiencia, que están en condiciones de acometer la realización de una planta de cemento en su totalidad.

El valor de la exportación total realizada desde aquí y de origen español, en los casos citados, ha supuesto unos ingresos en divisas en estos años superiores a los 14 mil millones de pesetas, lo que confirma la creciente relevancia de este sector de actividad industrial y en la balanza comercial.

Las previsiones de los nuevos proyectos que se están en estos momentos discutiendo, pueden representar otros 4 ó 5 mil millones de pesetas más.

No se han tenido presente en estos datos y referencias las exportaciones de partes, elementos y componentes de fábricas de cemento, como molinos, testeros, hornos, virolas, elementos de intercambiadores, maquinaria eléctrica, filtros, etc., que se exportan con una cierta frecuencia a varios paises.

En cuanto se refiere a diversidad y distribución geográfica, las realizaciones señaladas llevadas a cabo en más de 10 países constituyen no sólo una notable lista de referencias, y un visible escaparate, sino además una avanzada y un exponente de nuestra capacidad y pujanza con notable efecto multiplicador.

Es curioso comprobar en este sentido cómo estos proyectos por su naturaleza y complejidad y diversidad de equipos que encierran, han servido a su vez para potenciar y ampliar la base de nuestras posibilidades.

Así, ya en fecha reciente estos proyectos han tenido lugar, debido al progresivo conocimiento del nivel industrial español a través de los contactos y visitas de clientes, técnicos y empresarios, quienes han visitado las industrias y realizaciones españolas, y se están suministrando equipos y maquinaria para canteras, equipos de transporte para cemento (FF.CC. y carretera), instalaciones de almacenamiento y carga a granel, líneas de producción de sacos de cemento, equipos de dosificación y centrales de hormigonado, etc., parte de los cuales de otra manera habría sido probablemente muy difícil exportar. 
Sin embargo, debe destacarse en honor a la verdad que en la consecución de estos contratos, en lo que se refiere a los elementos de convencimiento y decisión que han influido de forma favorable a las propuestas españolas, el aspecto del financiamiento ha jugado un papel fundamental.

Igualmente puede decirse en cuanto afecta a las realizaciones con los licenciatarios antes señalados, para convencerles de actuar a través de España, o ceder sus procesos y licencias a firmas españolas para acudir a los mercados exteriores.

Si en un principio la obtención de estos permisos y autorizaciones ha sido una verdadera labor de paciencia y un esfuerzo notable de imaginación y capacidad de convencimiento, ya a estas alturas, después del tiempo transcurrido y a la vista de la utilidad que representa para ellos, como ampliación del campo de sus posibilidades, es relativamente fácil y rápido el entendimiento.

No quiere ello significar en absoluto que esta situación de depenedencia tecnológica sea la correcta ni pueda y deba tener carácter estable. Es, más que posible, seguro, que la evolución y desarrollo industrial de países que hoy constituyen o han constituido la clientela española, por la lógica y normal evolución de las economías, traten no sólo de autoabastecerse, sino de repetir el caso español en terceros mercados.

Ya es casi una realidad que países como Brasil y Argentina, a los que no hace muchos años hemos exportado plantas completas, no sólo se autoabastezcan con su propia industria, sino que aparezcan (como ya lo están haciendo de hecho) en mercados limítrofes y vecinos en competencia con nosotros.

Tal es el ejemplo de estos países en el mercado del ALALC y del Pacto Andino, donde gozan además de ventajas y preferencias que dificultan y pueden hacer imposible incluso en el futuro nuestra participación.

A su vez, todos estos países se ven obligados a adquirir o importar tecnología y licencias para poder operar, y aparece como mucho más problemático y lejano el que puedan llegar a ser autosuficientes en este terreno.

Debe ello constituir un acicate para nosotros, en el esfuerzo de lograr no ya crear una tecnología absolutamente propia en todas las disciplinas y especialidades que intervienen en una planta de cemento, pero sí disponer de la libertad de acción en su empleo, tratando de "españolizar" al máximo las técnicas y procedimientos.

Decíamos anteriormente que el aspecto financiero constituía un elemento determinante de nuestra acción en los mercados exteriores. Ello, además de ser un hecho cierto y comprobado, viene a ser ya un denominador común en todas las ocasiones.

En los casos de los que yo tengo noticia en los últimos años, que por nuestra situación y conocimiento son casi todos, no recuerdo ni uno solo en el que, dentro de las condiciones de la negociación, no fuera condición "sine qua non" el ofrecimiento de condiciones de financiamiento.

Estas condiciones han podido ser satisfechas desde hace años gracias y a través del sistema de seguro y crédito a la exportación española.

Desde España es posible financiar la totalidad de los servicios de:

- Estudio, proyecto e ingeniería completos.

- Suministro de todos los equipos, materiales e instalaciones de origen español, incorporando a su vez hasta un máximo de un $10 \%$ de origen extranjero si fuese necesario.

- El transporte y los seguros de transporte, montaje y obra. 
- El montaje, su supervisión y dirección y la puesta en marcha de la planta; siempre que sean prestados por empresas o firmas españolas.

De este importe se puede llegar a financiar hasta el $90 \%$ del mismo, con plazos de amortización de hasta 7 años para plantas completas, comenzando éstas después de la puesta en operación de la misma.

En general estas condiciones se han demostrado como competitivas y suficientes en la mayoría de los casos, aunque han sido sobrepasadas, en casos muy excepcionales, la mayor parte de las veces por razones de competencia externa.

Como señalábamos al principio, la experiencia y los resultados han sido alentadores y cabe mirar al futuro con esperanza. Se ha ganado confianza en nosotros mismos de una parte, y se ha podido convencer en muchos casos tanto a compradores como a licenciatarios de nuestra capacidad a una y utilidad a otros.

Sin embargo, es preciso reconocer que la competencia internacional, de una parte, y la protección a las industrias nacionales de los respectivos países, de otra, están haciendo las cosas cada vez más difíciles y las condiciones más duras y exigentes.

En estos momentos nuestra capacidad y libertad de acción es bastante más amplia que en un principio, y la labor de conocimiento y propaganda llevada a cabo implícitamente con las propias acciones desarrolladas más bien que como un propósito decidido propio y específico, están dando sus frutos.

Queda por insistir en la absoluta necesidad e imperiosa urgencia de "nacionalizar y españolizar" la técnica, y en este empeño al sector cliente en España le cabe una responsabilidad a la que debe hacer frente, prestando su colaboración y ayuda. 
1. Abierto por el Presidente, Sr. ARREDONDO, lo inició el Sr. GASPAR felicitando a SERCOBE por su labor de ámbito mundial y haciendo al Sr. LAFORGUE una pregunta acerca de su opinión sobre la presencia y la participación española en Iberoamérica, en cuanto a "fabricación y empleo de materia gris": materia gris "hombre" y materia gris "cemento".

Le respondió el Sr. LAFORGUE diciendo que, con respecto al hombre, hay grupos cementeros españoles asociados a empresas de proyectos, y capacitados para el suministro de plantas. Estas asociaciones se hacen por formación de capital común, por pertenencia a un mismo grupo bancario.

Por otra parte - prosiguió-, me consta el resultado satisfactorio de la formación de técnicos - concretamente en el caso de los brasileños-, en España, los cuales han sido acogidos con los brazos abiertos por las empresas españolas, sin que estas cobraran por este servicio, aun teniendo derecho a ello por contrato. El resultado de esta labor ha sido sorprendente; los latinoamericanos son listos, aprenden pronto, en tiempos récord, y se acoplan bien a nuestras fábricas y sistemas de producción. Por otra parte - continuó-, les gusta el contacto humano con quienes en nuestras industrias realizan labores similares a las suyas, y quieren conocer acerca de sus problemas y de sus soluciones para los mismos, más que saber cómo se hace uso de un manual de manejo de un determinado aparato o equipo.

En cuanto a inversiones de empresas cementeras propiamente dichas - siguió el Sr. LAFORGUE-, ha habido intentos, aunque no sé de ninguno — dijo-, que haya culminado ya en la construcción de una fábrica con inversión directa española. Algunos grupos han estudiado esa posibilidad, porque en ciertos países iberoamericanos hay mercados interesantes, porque estos son perfeccionistas, porque las reglamentaciones en cuanto a contaminación ambiental son generalmente poco estrictas, porque se encuentra mano de obra fácil de formar, etc. Sin embargo, — prosiguió-, parece que la crisis energética afecta a la industria cementera en todo el mundo, y yo no sé - dijo-, hasta qué punto estas inversiones requieren un estudio minucioso de las condiciones locales. Creo -continuó diciendo-, que más que a la implantación total de empresas españolas, se llegará en algunos de estos países a participaciones sustanciales en el capital de las empresas clientes, lo cual está muy favorecido por la ley de inversiones en el exterior, que permite incluso la financiación de alguna de estas inversiones cuando ello ayuda a la exportación española, cosa que se da aunque sólo sea por la exportación, muy valiosa, de la planta en sí. Las inversiones se pueden asegurar además mediante pólizas que cubren un alto porcentaje de las pérdidas que pudieran producirse en la empresa situada en uno de aquellos países. Creo - concluyó-, que se va hacia esa solución, porque otros mercados importantes de la zona, como es el norteamericano, suelen tener déficits periódicos de cemento. Por otra parte - dijo-, el desarrollo de estos países sigue directrices bastante diferentes de uno a otro, lo que fomenta un mercado internacional local de cemento bastante alto, al que la exportación española, primera del mundo, aporta una experiencia muy valiosa. 
2. El Sr. SORIA preguntó después acerca de relaciones con países socialistas. Le respondió el Sr. LAFORGUE que las experiencias más claras habidas con ellos son las de Yugoslavia y Cuba. A la primera se le han hecho ofertas, algunas ya en proceso de negociación. En general se ha ido allí de la mano de empresas de origen alemán, y se da la circunstancia de que se exigen muy altos porcentajes de financiación local, porque tratan de reducir la tasa de inflación que es muy elevada.

En cuanto a otros mercados socialistas - continuó-, no hay experiencia de exportación de plantas completas, sino sólo de piezas y equipos de fundición, así como de elementos de regulación y control, y hecha también de la mano de otras firmas y bajo la modalidad de una contrapartida española. En algunos casos, como el de Polonia, esta contrapartida es relativamente fácil de encontrar; en otros no tanto. Otro problema para alguno de estos países suele ser el de la financiación local. Sin embargo - siguió diciendo el Sr. LAFORGUE—, creo que se tenderá cada vez más a exportar a los países socialistas por una razón sencilla: sus techos de endeudamiento con la República Federal de Alemania, su tradicional proveedor, están muy cerca de ser alcanzados, por lo que podrían comprar ya muy poco financiado en ella. Pero para la República Federal Alemana es muy cómodo en estos casos disponer de un país en que como España tienen sus filiales, del que conocen los equipos, y que además puede ofrecer una financiación por estar tales países lejos de su techo de endeudamiento con relación a nosotros. Por ello -añadió-, la situación española es ideal, aunque hay muchos problemas que resolver, porque las negociaciones con los países socialistas han sido siempre muy lentas, dado su sistema de trabajo distinto del nuestro.

En cuanto a Cuba - prosiguió el Sr. LAFORGUE-, se han llevado a cabo importantes realizaciones de plantas completas, dado que es un país menos tecnificado. No obstante, el porvenir de la exportación española de equipos a Cuba se ve muy oscuro, porque sus ingresos de divisas - proceden principalmente de la venta de azúcar, y bien conocida es la triste evolución que para los países exportadores ha tenido su precio. Además, metido como está el país en un programa de desarrollo industrial bastante amplio, es muy posible que frene-toda realización futura hasta que se recupere el precio mundial del azúcar, lo cual puede llevar bastantes años. Generalmente -aclaró —, los ciclos del precio del azúcar suelen ser de siete años, y puesto que hace dos estábamos en el máximo, quedan otros cinco en que el mercado cubano de exportación de bienes de equipo va a estarnos vedado.

3. El Sr. PAZ preguntó finalmente como funciona el SERCOBE y cómo manejan las relaciones comerciales con Iberoamérica los fabricantes españoles interesados en hacer inversiones en ultramar.

En este momento el Sr. ARREDONDO dijo que si no había ninguna pregunta más sugería que la explicación detallada de lo que es y de cómo funciona el SERCOBE se diese en privado, porque evidentemente había de ser muy larga; pero que si había más personas interesadas en ella, que entonces se diese en la sala.

Al no ser así, y contando con la comprensión del Sr. PAZ, el Presidente, Sr. ARREDONDO, agradeció la ponencia del Sr. BARON y la presentación del Sr. LAFORGUE, así como las participaciones en el Coloquio, dando éste por concluido. 